\title{
A Retrospective Study of Cleft lip and palate Patients' Satisfaction after Maxillary Distraction or Traditional Advancement of the Maxilla
}

\author{
Kristian Andersen ${ }^{1}$, Sven Erik Nørholt ${ }^{1}$, Annelise Küseler ${ }^{1}$, John Jensen ${ }^{1}$, Thomas Klit Pedersen ${ }^{1}$ \\ ${ }^{1}$ Department of Oral and Maxillofacial Surgery, Aarhus University Hospital, Aarhus, Denmark. \\ ${ }^{2}$ Department of Oral and Maxillofacial Surgery and Oral Pathology, School of Dentistry, Aarhus University, Aarhus, Denmark. \\ ${ }^{3} \mathrm{Cleft}$ Palate Institute, Aarhus University Hospital, Aarhus, Denmark.
}

\author{
Corresponding Author: \\ Kristian Andersen \\ Aarhus University Hospital \\ Department of Oral and Maxillofacial Surgery \\ Nørrebrogade 44, 8000 Aarhus \\ Denmark \\ Phone: +4589492970 \\ Fax: +4589492930 \\ E-mail: krisae@,rm.dk
}

\begin{abstract}
Objectives: To compare cleft lip and palate patients' satisfaction with aesthetics and functional parameters after conventional advancement of the maxilla or by the use of distraction osteogenesis.

Material and methods: Case series observational study. Group of distraction osteogenesis (DO) consisted of 15 patients treated with distraction osteogenesis while group conventional (CONV) included 10 patients treated with traditional advancement of the maxilla. Patients were asked to fill out a questionnaire about their subjective evaluation of satisfaction with facial aesthetics and functional parameters on a continuous visual analog-scale (VAS) when the treatment was finished. Results: The total response rate was $76 \%$. Preoperatively the two groups did not differ significantly according to group characteristics. At follow-up both groups were satisfied with aesthetics and functional parameters. The DO group was less satisfied with the duration of the treatment than the CONV group. There were no statistically significant differences among the groups regarding functional parameters or facial aesthetics.

Conclusions: Cleft lip and palate patients experienced a high level of satisfaction with functional parameters and aesthetics as a result of surgical maxillary advancement. The patients treated with distraction osteogenesis were less satisfied with the duration of the treatment. Further studies are needed.
\end{abstract}

Keywords: distraction osteogenesis; quality of life; cleft lip; cleft palate; Le Fort osteotomy.

Accepted for publication: 22 May 2012.

To cite this article:

Benninger B, Rossb A, Delamarter T. Approaches to Proximal Tibial Bone Harvest Techniques.

J Oral Maxillofac Res 2012 (Apr-Jun);3(2):e3

URL: http://www.ejomr.org/JOMR/archives/2012/2/e3/v3n2e3ht.pdf

doi: $10.5037 /$ jomr.2012.3203 


\section{INTRODUCTION}

Cleft lip and palate (CLP) patients are going through an extensive treatment with orthodontic and surgical correction of the position of teeth and hard and soft tissues. The aim of the primary surgery is to close the clefts of the lip and the soft palate. Transversal expansion of the dental arch is done by orthodontics and orthopaedics. The aim of the secondary surgery is to close the cleft of the alveolus by bone grafting. Surgery of the clefts induces formation of scar tissue, which affects the soft tissue matrix that guides the development of the maxillary complex. The scar tissue as well as a reduced growth of the mid face often causes a maxillary retrognatism, that adversely affects the chewing function, the ability to speak, the facial aesthetics [1], social life [2] as well as psychological and general wellbeing of the CLP-patients [ 3$]$. For that reason, between 25 to $60 \%$ of the CLP-patients need a surgical treatment of the maxillary retrognatism [4]. This surgical-orthodontic treatment is the last part of the rehabilitation of the CLP-patient, which has the objective to create a good dental occlusion and function, more harmonic facial aesthetics and increase the quality of life. Since the 1970's the standard treatment of CLPpatients with a maxillary hypoplasia has been a Le Fort I osteotomy with a bone graft [5]. Treating extensive sagittal discrepancies maxillary surgery has to be combined with mandibular set-back. Maxillary surgery is difficult in CLP-patients because of the scar tissue, a tendency to relapse, poor bone quality and quantity and a reduced blood supply in the affected area [6]. These conditions are responsible for a typical relapse of 20 $25 \%[\underline{7}, \underline{8}]$. To compensate for this an overcorrection is often made during the surgical procedure [7], which can lead to an unpredictable final result.

Polley and Figueroa [9] described the use of distraction osteogenesis (DO) as an alternative treatment of maxillary hypoplasia using an external bone distraction device. The principle of this treatment was to induce formation of immature bone in the gap after a Le Fort I osteotomy by gradual tensile strength separating the two segments [10]. Studies of the treatment have shown a significantly reduced tendency of relapse [11], favourable changes of the soft tissue [12] and changes of the velopharyngeal closure similar to that of conventional advancement [13].

The duration of the course of treatment is up to 16 weeks longer when choosing DO. In this period the appliance penetrates the buccal mucosa in the sulcus and the patient must take care of the daily activation and keep it clean.

The aim of this retrospective pilot study was to examine and compare the cleft lip and palate patients' satisfaction after treatment with either maxillary distraction or traditional advancement of the maxilla after a Le Fort I osteotomy.

\section{MATERIAL AND METHODS}

In the period 1996 - 2007 forty-two CLP-patients with need for advancement of the maxilla were surgically treated at the Department of Oral and Maxillofacial Surgery, Aarhus University Hospital by either traditional advancement of the maxilla or distraction osteogenesis. Until 2000 the standard regime of treatment was a traditional advancement of the maxillary complex after Le Fort I osteotomy. Since 2000 maxillary distraction has provided an alternative in treatment of CLP-patients requiring a maxillary advancement of $10 \mathrm{~mm}$ or more. Consequently, the patients in this study consisted of two groups of CLP-patients with the need for surgicalorthodontic correction of maxillary hypoplasia. A criterion for both groups was that the postsurgical orthodontics had to be finished if the patient was to be included in the study. Conventional group (CONV) included patients treated with traditional advancement of the maxilla after a Le Fort I osteotomy in the period 1996 - 2007. The group DO included patients treated with maxillary distraction (Table 1).

Fifteen patients met the inclusion criteria in the DO group and ten patients in the CONV group. The composition of the two groups according to gender, type of cleft, type of distraction, type of distractors used, age at surgery and type of surgery performed is presented in Table 1. Group DO consisted of 10 males and 5 females with a mean age at the time of surgery of 17.5 (SD 2.3) years while group CONV consisted of 5 males and 5 females with a mean age at the time of surgery of 17.8 (SD 2.6) years.

A quantitative method, a questionnaire, was used to investigate the patients' satisfaction in the two groups. Existing literature was reviewed and a list of relevant subjects was made and operationalized in a questionnaire containing 13 questions about the patients' perception of aesthetics and function.

The patients were asked to answer by making a mark on a visual analog-scale (VAS) scaled 0 - 100 [14]. The score 0 indicating the highest level of satisfaction with functional parameters or facial aesthetics and the score 100 indicating the lowest level of satisfaction. The end points of the scales were unequivocal and easy to understand, for example no pain / intolerable pain; very satisfied / very unsatisfied; no discomfort / worst imaginable discomfort. The accompanying 
Table 1. Patients' characteristics according to gender, type of cleft, type of surgery performed, type of distractors used and age at surgery

\begin{tabular}{|c|c|c|c|c|c|}
\hline $\begin{array}{c}\text { Patient } \\
\#\end{array}$ & Gender & Type of cleft & Type of surgery & Type of distractors & $\begin{array}{c}\text { Age at surgery } \\
\text { (years) }\end{array}$ \\
\hline 1 & $\mathrm{~F}$ & UCLP & LF-1 + int. DO & Synthes & 16 \\
\hline 2 & M & Cl. III & LF-1 + int. DO & KLS Martin & 16 \\
\hline 3 & M & UCLP & LF-1 + int. DO & KLS Martin & 19.5 \\
\hline 4 & $\mathrm{~F}$ & BCLP & $\mathrm{LF}-1+$ ex. $\mathrm{DO}^{\mathrm{b}}$ & RED, KLS Martin & 15 \\
\hline 5 & M & UCLP & LF-1 + int. DO & Synthes & 17.5 \\
\hline 6 & M & Oxycephalia & LF-1 + int. DO & Synthes & 15.5 \\
\hline 7 & M & UCLP & LF-1 + ex. DO ${ }^{b}$ & RED, KLS Martin & 15.7 \\
\hline 8 & M & UCLP & $\mathrm{LF}-1+$ int. $\mathrm{DO}^{\mathrm{a}}$ & KLS Martin & 20.5 \\
\hline 9 & F & BCLP & $\mathrm{LF}-1+$ int. DO & Synthes & 23 \\
\hline 10 & M & BCLP & $\mathrm{LF}-1+$ int. $\mathrm{DO}^{\mathrm{a}}$ & Synthes & 17 \\
\hline 11 & M & UCLP & LF-1 + int. DO & Synthes & 16.5 \\
\hline 12 & M & BCLP & $\mathrm{LF}-1+$ int. $\mathrm{DO}^{\mathrm{a}}$ & Synthes & 19 \\
\hline 13 & $\mathrm{~F}$ & UCLP & LF-1 + int. DO & Synthes & 17.5 \\
\hline 14 & M & BCLP & LF-1 + int. DO & Synthes & 19 \\
\hline 15 & $\mathrm{~F}$ & BCLP & LF-1 + int. DO & Synthes & 15 \\
\hline 16 & $\mathrm{~F}$ & BCLP & Seg. LF-1 ${ }^{\mathrm{d}}$ & - & 16 \\
\hline 17 & M & BCLP & $\mathrm{LF}-1^{\mathrm{c}}$ & - & 20 \\
\hline 18 & $\mathrm{~F}$ & UCLP & LF-1 ${ }^{\mathrm{c}}$ & - & 24 \\
\hline 19 & $\mathrm{~F}$ & UCLP & Seg. LF-1 ${ }^{\mathrm{d}}$ & - & 16 \\
\hline 20 & $\mathrm{~F}$ & UCLP & $\mathrm{LF}^{-1}{ }^{\mathrm{c}}$ & - & 16 \\
\hline 21 & M & UCLP & $\mathrm{LF}-1+\mathrm{BSSO}^{\mathrm{e}}$ & - & 17 \\
\hline 22 & M & BCLP & LF-1 ${ }^{\mathrm{c}}$ & - & 17 \\
\hline 23 & $\mathrm{~F}$ & BCLP & LF-1 ${ }^{\mathrm{c}}$ & - & 16 \\
\hline 24 & M & UCLP & Seg. LF- $1^{d}$ & - & 19 \\
\hline 25 & M & UCLP & LF-1 ${ }^{c}$ & - & 17 \\
\hline
\end{tabular}

aUnsegmented Le Fort I osteotomy and internal distraction.

${ }^{b}$ Unsegmented Le Fort I osteotomy and external distraction.

'Unsegmented Le Fort I osteotomy.

dSegmented Le Fort I osteotomy.

eUnsegmented Le Fort I osteotomy and a bilateral sagittal split osteotomy.

$\mathrm{M}=$ male; $\mathrm{F}=$ female; UCLP $=$ unilateral cleft lip and palate; $\mathrm{BCLP}=$ bilateral cleft lip and palate; $\mathrm{Cl}$. III $=$ class three sagittal jaw relationship.

letter contained information about the aim of the study and how to answer. The patients were asked to return the questionnaire by pre-paid mail after two weeks. Non-responders were followed-up after one month. The study was approved by The Central Denmark Region Committees on Biomedical Research Ethics.

\section{Treatment procedures}

All patients had presurgical orthodontic treatment and were treated surgically with a high Le Fort I osteotomy. In the CONV group the treatment was a conventional combined orthodontic-surgical treatment with model surgery and splint fabrication for the maxillary position and completed with postsurgical orthodontics. The patients in the CONV group had an average advancement of $6.98 \mathrm{~mm}$ (range $5-11 \mathrm{~mm}$ ). Patients from the DO group had the distraction device placed in pre-planned position calculated from lateral cephalograms and adjusted on a three-dimensional print of the skull based on a computed tomography (CT) or a cone beam CT (CBCT).

The appliances used for distraction were Synthes internal distractor (Synthes, West Chester, PA, USA), KLS Martin internal distractor (KLS Martin Group, Tuttlingen, Germany) and Rigid External Device (RED) KLS Martin (KLS Martin Group, Tuttlingen, Germany) for the external distraction procedures (Table 1).

All the patients treated with distraction were registered for model surgery using the same procedure as for the conventional treated patients using face bow registration, wax bite and articulator mounting. 
The patients had surgical splints fabricated and in the cases of DO the splint was used as a guide for using intermaxillary elastics after the active distraction. The maxilla was thereby manipulated into the final planned position. In five of the DO patients the palatal defect caused an unstable intersegmental position. The use of the splint was refrained from and intermaxillary elastics were used to guide the segments into occlusion.

During the surgical procedure the internal distraction devices were adapted to the maxilla in the planned position. The screw holes were marked and the devices were removed in order to complete the Le Fort I osteotomy. After ensuring mobility of the maxilla the devices were fixed to the maxilla and tested for interference free activation.

The mean latency period after device placement was 4.9 days (range $4-7$ days). During the active phase of distraction the appliances were activated on a daily basis either by the patient or an assistant, usually a family member. Activation was done twice a day with a rate of $0.5 \mathrm{~mm}$, corresponding to $1.0 \mathrm{~mm}$ daily. Activation went on until the planned position of the maxilla was achieved and intermaxillary elastics were then used to adjust the final position. The mean period of active distraction was 17.7 days (range 13 - 28 days) and the mean advancement of the maxilla was $12 \mathrm{~mm}$ (range $6-16 \mathrm{~mm}$ ). After an average consolidation period of 77.3 days (range 35 - 213 days), the patients were readmitted and the devices removed in general anaesthesia. Postsurgical orthodontics completed the treatment. In the CONV group the treatment was a conventional combined orthodontic-surgical treatment with model surgery and splint fabrication for the maxillary position and completed with postsurgical orthodontics.

\section{Statistical analysis}

Unpaired t-tests were performed to analyse intergroup differences regarding duration of orthodontic treatment and VAS-scores in SPSS 18.0 (IBM, USA).
Statistical significance was defined as $\mathrm{P}<0.05$.

\section{RESULTS}

The duration of the orthodontic treatment was in average 10 months longer in the DO group than the CONV group and this difference was significant $(\mathrm{P}<0.05)$. Neither the age distribution nor the period of time between surgery and completion of the questionnaire differed significantly $(\mathrm{P}<0.05)$ (Table 2$)$. Nineteen out of 25 patients returned the questionnaires and the total response ratio was $76 \%$. The response ratio for the DO group was $87 \%$ and for CONV $60 \%$. The results are presented in Table 3 . As the groups were small the data will only be presented descriptively.

Both groups felt a great deal of satisfaction with their appearance both according to themselves and the perceptions of relatives and other people's reaction in general. Both groups were satisfied with their general well being and felt few restrictions or discomfort during social activities. According to functional parameters the groups were alike. Both groups were minimally affected by pain and sensory disturbances and reported a great deal of satisfaction with speech and breathing. The discomfort during eating and drinking and sleep were low as well in both groups. The greatest difference occurred in the parameter satisfaction with the duration of the treatment course. The DO group scored higher on the VAS-scale according to less satisfaction with the duration than the CONV group. Statistical analyses revealed no significant differences $(P>0.05)$ among the groups which may be explained by the numbers of patients included in the study.

\section{DISCUSSION}

Distraction osteogenesis has become a widely used treatment of maxillary hypoplasia in CLPpatients because of the reports of better stability and

Table 2. Distribution of the patients' groups according to gender, age at surgery and period between surgery and completion of the questionnaire

\begin{tabular}{ccccc}
\hline & $\begin{array}{c}\text { Gender } \\
\text { (male/female) }\end{array}$ & $\begin{array}{c}\text { Age at surgery } \\
\text { (M years [SD]) }\end{array}$ & $\begin{array}{c}\text { Duration of } \\
\text { orthodontic treatment } \\
(\text { M months [SD]) }\end{array}$ & $\begin{array}{c}\text { Period between surgery and } \\
\text { completion of the questionnaire } \\
\text { (M months [SD]) }\end{array}$ \\
\hline DO & $10 / 5$ & $17.5(2.3)$ & $28.7(7.4)^{\mathrm{c}}$ & $24.8(19)^{\mathrm{a}}$ \\
CONV & $5 / 5$ & $17.8(2.6)$ & $18.4(5.9)^{\mathrm{c}}$ & $24.4(11)^{\mathrm{b}}$ \\
\hline
\end{tabular}

aAfter the primary surgery with insertion of the distractors.

${ }^{\mathrm{b}}$ After the surgical procedure.

'Unpaired t-test, states $\mathrm{P}<0.05$ between patients of $\mathrm{DO}$ and CONV groups.

$\mathrm{M}(\mathrm{SD})=$ mean $($ standard deviation). 
Table 3. Results of the patients' satisfaction on a continuous visual analog-scale (VAS)

\begin{tabular}{|c|c|c|}
\hline VAS question ${ }^{\mathrm{a}}$ & $\begin{array}{c}\text { DO group } \\
(n=13) \\
\text { (M VAS }[\mathrm{SD}])\end{array}$ & $\begin{array}{l}\text { CONV group } \\
(n=6) \\
(M \text { VAS }[\mathrm{SD}])\end{array}$ \\
\hline The patients satisfaction with appearance & $5(10)$ & $10(12)$ \\
\hline Families satisfaction with appearance & $5(9)$ & $13(26)$ \\
\hline Other peoples reaction because of appearance & $8(12)$ & $11(20)$ \\
\hline Extent of pain from the jaws & $11(22)$ & $13(29)$ \\
\hline Extent of sensory disturbances & $10(17)$ & $16(26)$ \\
\hline General well being in everyday life & $4(7)$ & $9(20)$ \\
\hline Restriction of social activities & $3(7)$ & $5(12)$ \\
\hline Discomfort during social activities & $3(5)$ & $7(16)$ \\
\hline Discomfort during eating and drinking & $2(9)$ & $5(12)$ \\
\hline Discomfort during falling asleep and sleep & $2(14)$ & $3(6)$ \\
\hline Affection of speech & $8(10)$ & $11(17)$ \\
\hline Affection of breathing & $1(3)$ & $8(18)$ \\
\hline Satisfaction with duration of treatment & $40(38)$ & $7(16)$ \\
\hline
\end{tabular}

a On a VAS-scale scaled 0 - 100 with the score 0 indicating the highest level of satisfaction with functional parameters or facial aesthetics and the score 100 indicating the lowest level of satisfaction.

$\mathrm{M}(\mathrm{SD})=$ mean (standard deviation)

the possibility for larger advancements $[\underline{15}, \underline{16}]$. However, it is a more complicated treatment because of the period with active distraction, the obligate need for good cooperation and the long consolidation phase with the patient still wearing the appliance. The present study is a pilot study and evaluates retrospectively patients' satisfaction in two groups of CLP-patients treated for maxillary hypoplasia with either maxillary distraction or conventional Le Fort I advancement. The number of patients was limited and especially the CONV group was small and the number of patients responding was lower than in the DO group.

The results indicated a high level of satisfaction with the facial aesthetic at the end of treatment in both the DO and the CONV group. The parameters pain and sensory disturbances did not differ a lot between the groups in this study. It could be hypothesized that more extensive osteotomies and preoperative advancements in CONV could induced more sensory disturbances and pain compared with a gradual movement and distraction histogenesis of soft tissues when using DO. Further studies should focus on this aspect.

The groups had comparable scores according to the functional parameters eating and drinking, sleep, speech and breathing. DO was significantly less satisfied with the duration of the treatment than CONV probably according to a longer duration of the orthodontic treatment. The influence of the period with the distractors mounted on the level of satisfaction was not measured but it can be hypothesized that this period is troublesome. Further studies of this period between mounting and removal is needed as the prolonged total treatment time is a disadvantage and perhaps the most important difference when choosing DO instead of conventional treatment. A greater understanding of the cellular processes during the period of distraction and the period of consolidation and possibility to accelerate the genesis and maturation of bone by the use of pharmacological agents could reduce the duration of these periods $[17,18]$. By a reduction of the duration of these aforementioned periods the probable inconveniences could be reduced and possibly of a greater patients' satisfaction and lesser discomfort could be achieved. Another way to reduce the strain on the DO patients would be the continuous development of the distractors, e.g. reduction in size, partly removable appliances, continuous activation etc. [19].

Patients' satisfaction in association with distraction is a subject sparsely examined in the existing literature. No studies describes patients' satisfaction during internal distraction while only a single retrospective survey with a quite small population has studied patients' satisfaction during external distraction.

Eggermont et al. [20] concluded that most of the patients receiving RED treatment had an increased satisfaction with facial aesthetics after the treatment than before the treatment in spite of a great deal of dissatisfaction with the facial aesthetics during the course of treatment. A long term study of patients' perception of function and satisfaction showed that orthognathic surgery resulted in a subjective estimation of function, appearance, 
health, and interpersonal relationships that was higher than that among pretreatment and no-treatment control groups [21]. A newly prospective study of patients receiving orthognathic surgery showed that perception of function and general satisfaction significantly increased after orthognathic surgery and that the parameters were positive correlated [22]. This study also showed a general high level of satisfaction with appearance and functional parameters in CLP-patients treated with either DO or conventional treatment.

The retrospective design of this survey and the two years between the operation and the completion of the questionnaire diminished the reliability of the patients' answers. The use of a questionnaires cause problems with the internal validity, because the questionnaire is designed with a limited amount of topics, that might not all be the most valid according to every single patient but representing a selection bias. Further use of this questionnaire necessitates a validation. Instead a validated questionnaire, for instance the Oral Health Impact Profile or Orthognathic Quality of Life Questionnaire can be used in further studies $[\underline{23}, \underline{24}]$.

The subject of this article needs further investigation. Prospective surveys should be based on a validated questionnaire and include the period between mounting and removal of the distractors. A comparative study of patients' satisfaction during three different courses of treatment, traditional advancement, external distraction and internal distraction, could probably lead to a greater understanding of this important subject.

\section{CONCLUSIONS}

1. Cleft lip and palate patients experience a high level of satisfaction with functional parameters and aesthetics after surgical-orthodontic treatment of maxillary hypoplasia.

2. Patients treated with distraction osteogenesis were less satisfied with the duration of their treatment than the conventional group.

3. Further studies are needed using validated questionnaires.

\section{ACKNOWLEDGEMENTS AND DISCLOSURE STATEMENTS}

The authors report no conflicts of interest related to this study. No external funding, apart from the support of the authors' institution, was available for this study.

\section{REFERENCES}

1. Meyer-Marcotty P, Stellzig-Eisenhauer A. Dentofacial self-perception and social perception of adults with unilateral cleft lip and palate. J Orofac Orthop. 2009 May;70(3):224-36. Epub 2009 May 31. English, German. [Medline: 19484415] [doi: 10.1007/s00056-009-8813-9]

2. Brand S, Blechschmidt A, Müller A, Sader R, Schwenzer-Zimmerer K, Zeilhofer HF, Holsboer-Trachsler E. Psychosocial functioning and sleep patterns in children and adolescents with cleft lip and palate (CLP) compared with healthy controls. Cleft Palate Craniofac J. 2009 Mar;46(2):124-35. Epub 2008 Jun 12. [Medline: 19254057] [doi: 10.1597/07-165.1]

3. Turner SR, Rumsey N, Sandy JR. Psychological aspects of cleft lip and palate. Eur J Orthod. 1998 Aug;20(4):407-15. Review. [Medline: 9753822] [doi: 10.1093/ejo/20.4.407] [FREE Full Text]

4. Rachmiel A. Treatment of maxillary cleft palate: distraction osteogenesis versus orthognathic surgery--part one: Maxillary distraction. J Oral Maxillofac Surg. 2007 Apr;65(4):753-7. [Medline: 17368374] [doi: 10.1016/j.joms.2006.08.010]

5. Houston WJ, James DR, Jones E, Kavvadia S. Le Fort I maxillary osteotomies in cleft palate cases. Surgical changes and stability. J Craniomaxillofac Surg. 1989 Jan;17(1):9-15. Review. [Medline: 2644310] [doi: 10.1016/S1010-5182(89)80121-0]

6. Baek SH, Lee JK, Lee JH, Kim MJ, Kim JR. Comparison of treatment outcome and stability between distraction osteogenesis and LeFort I osteotomy in cleft patients with maxillary hypoplasia. J Craniofac Surg. 2007 Sep;18(5):120915. [Medline: 17912117 ] [doi: $10.1097 / \mathrm{scs} .0 \mathrm{~b} 013 \mathrm{e} 31814 \mathrm{~b} 2 \mathrm{~b} 8 \mathrm{c}]$

7. Posnick JC, Dagys AP. Skeletal stability and relapse patterns after Le Fort I maxillary osteotomy fixed with miniplates: the unilateral cleft lip and palate deformity. Plast Reconstr Surg. 1994 Dec;94(7):924-32. [Medline: 7972480] [doi: 10.1097/00006534-199412000-00004]

8. Hirano A, Suzuki H. Factors related to relapse after Le Fort I maxillary advancement osteotomy in patients with cleft lip and palate. Cleft Palate Craniofac J. 2001 Jan;38(1):1-10. [Medline: 11204674] [doi: 10.1597/1545-1569(2001)038<0001:FRTRAL >2.0.CO;2]

9. Polley JW, Figueroa AA. Management of severe maxillary deficiency in childhood and adolescence through distraction osteogenesis with an external, adjustable, rigid distraction device. J Craniofac Surg. 1997 May;8(3):181-5; discussion 186. [Medline: 9482064] [doi: 10.1097/00001665-199705000-00008]

10. Swennen G, Schliephake H, Dempf R, Schierle H, Malevez C. Craniofacial distraction osteogenesis: a review of the literature: Part 1: clinical studies. Int J Oral Maxillofac Surg. 2001 Apr;30(2):89-103. Review. [Medline: 11405458] [doi: 10.1054/ijom.2000.0033] 
11. Cheung LK, Chua HD, Hägg MB. Cleft maxillary distraction versus orthognathic surgery: clinical morbidities and surgical relapse. Plast Reconstr Surg. 2006 Sep 15;118(4):996-1008; discussion 1009. [Medline: 16980862]

12. Wen-Ching Ko E, Figueroa AA, Polley JW. Soft tissue profile changes after maxillary advancement with distraction osteogenesis by use of a rigid external distraction device: a 1-year follow-up. J Oral Maxillofac Surg. 2000 Sep;58(9):95969; discussion 969-70. [Medline: 10981975] [doi: 10.1053/joms.2000.8735]

13. Chanchareonsook N, Samman N, Whitehill TL. The effect of cranio-maxillofacial osteotomies and distraction osteogenesis on speech and velopharyngeal status: a critical review. Cleft Palate Craniofac J. 2006 Jul;43(4):477-87. [Medline: 16854207]

14. Scott J, Huskisson EC. Graphic representation of pain. Pain. 1976 Jun;2(2):175-84. [Medline: 1026900] [doi: 10.1016/0304-3959(76)90113-5]

15. Figueroa AA, Polley JW, Friede H, Ko EW. Long-term skeletal stability after maxillary advancement with distraction osteogenesis using a rigid external distraction device in cleft maxillary deformities. Plast Reconstr Surg. 2004 Nov;114(6):1382-92; discussion 1393-4. Review. [Medline: 15509923] [doi: 10.1097/01.PRS.0000138593.89303.1B]

16. Rachmiel A, Aizenbud D, Peled M. Long-term results in maxillary deficiency using intraoral devices. Int J Oral Maxillofac Surg. 2005 Jul;34(5):473-9. [Medline: 16053864] [doi: 10.1016/j.ijom.2005.01.004]

17. Cheung LK, Zheng LW. Effect of recombinant human bone morphogenetic protein-2 on mandibular distraction at different rates in an experimental model. J Craniofac Surg. 2006 Jan;17(1):100-8; discussion 109-10. [Medline: 16432416] [doi: $10.1097 / 01 . s c s .0000188744 .06723 .1 \mathrm{f}]$

18. de Freitas PH. Re: evaluation of recombinant human bone morphogenetic protein-2 in mandibular distraction osteogenesis in rabbits: effect of dosage and number of doses on formation of bone. Br J Oral Maxillofac Surg. 2007 Jan;45(1):91-2. Epub 2006 Mar 15. [Medline: 16540216] [doi: 10.1016/j.bjoms.2005.11.024]

19. Djasim UM, Wolvius EB, Bos JA, van Neck HW, van der Wal KG. Continuous versus discontinuous distraction: evaluation of bone regenerate following various rhythms of distraction. J Oral Maxillofac Surg. 2009 Apr;67(4):818-26. [Medline: 19304040] [doi: 10.1016/j.joms.2008.08.016]

20. Eggermont B, Jansma J, Bierman MW, Stegenga B. Patient satisfaction related to rigid external distraction osteogenesis. Int J Oral Maxillofac Surg. 2007 Oct;36(10):896-9. Epub 2007 Jul 23. [Medline: 17646084] [doi: 10.1016/j.ijom.2007.05.018]

21. Lazaridou-Terzoudi T, Kiyak HA, Moore R, Athanasiou AE, Melsen B. Long-term assessment of psychologic outcomes of orthognathic surgery. J Oral Maxillofac Surg. 2003 May;61(5):545-52. [Medline: 12730832] [doi: 10.1053/joms.2003.50107]

22. Øland J, Jensen J, Melsen B. Factors of importance for the functional outcome in orthognathic surgery patients: a prospective study of 118 patients. J Oral Maxillofac Surg. 2010 Sep;68(9):2221-31. Epub 2010 Jul 8. [Medline: 20619525] [doi: 10.1016/j.joms.2010.01.025]

23. Slade GD, Spencer AJ. Development and evaluation of the Oral Health Impact Profile. Community Dent Health. 1994 Mar;11(1):3-11. [Medline: 8193981]

24. Cunningham SJ, Garratt AM, Hunt NP. Development of a condition-specific quality of life measure for patients with dentofacial deformity: I. Reliability of the instrument. Community Dent Oral Epidemiol. 2000 Jun;28(3):195-201. [Medline: 10830646] [doi: 10.1034/j.1600-0528.2000.280305.x]

\section{To cite this article:}

Andersen K, Nørholt SE, Küseler A, Jensen J, Pedersen TK. A Retrospective Study of Cleft lip and palate Patients' Satisfaction after Maxillary Distraction or Traditional Advancement of the Maxilla.

J Oral Maxillofac Res 2012;3(2):e3

URL: http://www.ejomr.org/JOMR/archives/2012/2/e3/v3n2e3ht.pdf

doi: $10.5037 /$ jomr.2012.3203

Copyright (C) Andersen K, Nørholt SE, Küseler A, Jensen J, Pedersen TK. Accepted for publication in the JOURNAL OF ORAL \& MAXILLOFACIAL RESEARCH (http://www.ejomr.org), 20 June 2012

This is an open-access article, first published in the JOURNAL OF ORAL \& MAXILLOFACIAL RESEARCH, distributed under the terms of the Creative Commons Attribution-Noncommercial-No Derivative Works 3.0 Unported License, which permits unrestricted non-commercial use, distribution, and reproduction in any medium, provided the original work and is properly cited. The copyright, license information and link to the original publication on (http://www.ejomr.org) must be included. 